\title{
Vertical Differentiation and Sequential Introduction for Versioned Information Products
}

\author{
Xiangchun Man*, Xiaode Zuo \\ School of Management, Jinan University, Guangzhou, China \\ Email: *manxiangchun@163.com
}

How to cite this paper: Man, X.C. and Zuo, X.D. (2019) Vertical Differentiation and Sequential Introduction for Versioned Information Products. Open Journal of Business and Management, 7, 1031-1041. https://doi.org/10.4236/ojbm.2019.72069

Received: April 4, 2019

Accepted: April 25, 2019

Published: April 28, 2019

Copyright $\odot 2019$ by author(s) and Scientific Research Publishing Inc. This work is licensed under the Creative Commons Attribution International License (CC BY 4.0).

http://creativecommons.org/licenses/by/4.0/

\section{Open Access}

\begin{abstract}
This article considers three situations when versioned information products introduce sequentially, then compares vertical differences and pricing strategies. The result shows that three equilibriums exist in the different sales orders under the vertical product differentiation. Price of high-versioned product will be highest when firm provides high-versioned product first then lowversioned product. It is the best strategy for covering the market and maximizing profits. For providing low-versioned product first then high-versioned product, the price of high-versioned product and the total market demands are affected by the waiting cost threshold. In addition, increasing of network externality will cause the increasing of the profit, price and demand of highversioned product, but the demand for low-versioned product will be reduced.
\end{abstract}

\section{Keywords}

Information Products, Versioning Strategy, Vertical Differentiation, Sequential Introduction

\section{Introduction}

Information products are common in the work and life of consumers. Versioning is a widely used sales method for information products. Version differences can meet different consumer needs and increase market share. For example, Microsoft sells Windows systems in a series of editions for the Home, Enterprise, Professional, and Gold. Information products with vertical differences apply to different consumer groups, with increasing market share. Different versions are sold at different prices, which can bring about an increase in profits. 
In reality, the information product versioning strategy is to meet the needs of more consumers and expand market share. This paper analyzes the vertical difference and pricing strategy of high and low versions based on maximizing market demand, as well as the impact of network externality on profit and market share.

\section{Related Literature}

\section{Stress and Counterproductive Work Behavior}

Many scholars have studied the vertical differences or version pricing of information products. Baake and Boom [1] studied the compatibility decision-making problem of enterprises under the network externality. They pointed out that, enterprises were more likely to obtain compatibility and higher profits under the interaction of vertical differences and network externalities. The research of Sundararajan [2] suggested that manufacturers influence the quality of products and pirated products through price discrimination. When there was no price discrimination, manufacturers always set lower quality. Bhargava and Choudhary [3] studied the versioning strategy of network externality. When the marginal utility was a constant, the two version strategy with quality differences was optimal. Noh and Moschinl [4] studied the different duopoly market in terms of product entry and containment strategies. Studies by Lee et al. [5] had shown that offering free products or services was to attract more consumers, expand the scale of the network, and then profit more by launching high-quality products or services. Nobuo [6] studied the Bertrand price competition strategy of Internet products with vertical differences between two monopolists. Chen and Seshadri [7] pointed out that manufacturers' development and pricing of information products are affected by the continuous heterogeneous external choices in the market. Wu and Chen [8] argued that the multi-version strategy was optimal in the presence of piracy. When there was no piracy, a single version was the best strategy. Bhargava and Choudhary [9] pointed out that information products were more favorable in product quality differentiation when the market share of low-quality products alone. Cheng and Tang [10] believed that a free version was the best choice when the network effect was strong. A study by Chappell et al. [11] showed that different versions of product quality evaluations led to product quality differences. Li et al. [12] studied the conditions for versioning of information products, and the number of versions, the determination of the difference in quality. They found that if the consumer utility was the linear utility function, the products with different qualities had willingness to pay. Hui et al. [13] believed that the information products that provided vertical differences were not affected by consumer heterogeneity. Lambertin and Tampieri [14] studied that if the market entry time was an endogenous variable, the equilibrium of observable delay games was the first to enter the market for low-quality enterprises.

From the above research, it can be found that the current research on the 
pricing of information products does not consider the difference in quality selection. This paper analyzes the vertical difference and pricing strategy of high and low versions based on maximizing market demand.

\section{Modeling}

In order to expand market share, the providers choose to sell multiple versions of information products. The vertical difference between the high version and the low version is the quality difference. Assuming the quality parameter of the high version is $s_{H}=1$, the quality parameter of the low version is $s_{L}=\lambda s_{H}=\lambda, \lambda \in(0,1)$ is the quality discount for the low version. Supposing the provider sells a lower version at a known price $\left(p_{L 0}\right)$. The price of the high version of the product is a decision variable $\left(p_{L 0}\right), p_{L 0}<p_{H}$. The consumer's evaluation of the quality of the product is $\theta \cdot s, \theta$ obeys uniform distribution $[0, V]$, represents the purchaser's evaluation of the unit quality product, $V$ is market capacity. The additional utility generated by network externalities is $\mu \cdot q \cdot s, \mu \in(0,1)$ indicates the network externality coefficient. When a consumer buys at most one unit of product, the consumer's utility is expressed as $\theta \cdot s-\mu \cdot q \cdot s-p$. Most of the studies often use such a representation. For the simplicity, assuming that the fixed cost and marginal cost of the information product is zero. In addition, the versioning cost of the product is not considered.

The utility function that consumers choose to different versions is:

$$
U=\left\{\begin{array}{l}
\left(\theta+\mu q_{H}\right) s_{H}-p_{H} \\
\left(\theta+\mu q_{L}\right) s_{L}-p_{L 0} \\
0
\end{array}\right.
$$

Total market demand $q=q_{H}+q_{L}$

$U_{H}=0, U_{L}=0$. The critical point for the evaluation value of purchasing the high and low version separately is:

$$
\theta_{H}=\frac{p_{H}}{s_{H}}-\mu q_{H}, \theta_{L}=\frac{p_{L}}{s_{L}}-\mu q_{L}
$$

$U_{H}=U_{L}$. The critical point for evaluating the difference between the purchase of the high version and the low version is:

$$
\theta_{H L}=\left(p_{H}-p_{L 0}\right) /\left(s_{H}-s_{L}\right)-\mu\left(q_{H}-q_{L}\right) /\left(s_{H}-s_{L}\right)
$$

The provider's revenue function is:

$$
\Pi=p_{H} q_{H}+p_{L 0} q_{L}
$$

The provider sells both versions of the information products, determining the quality discount $\lambda$ of the lower version according to the maximum demand firstly, selling at a known price $p_{L 0}$, and then deciding the sales price of the high version $p_{H}$. according to the profit maximization.

In the order of sequential sales of different versions, considering three strategies: 1) simultaneous selling high version and low version; 2) first selling high version, then selling low version; 3) first selling low version, then selling high 
version. Consider the following separately:

\subsection{Simultaneous Selling High Version and Low Version}

When $\theta \in\left[0, \theta_{L}\right)$, consumers do not buy any products. When $\theta \in\left[\theta_{L}, \theta_{H L}\right]$, consumers buy low version. When $\theta \in\left[\theta_{H L}, V\right]$, consumers buy high version (Figure 1).

The demand function is

$$
\left\{\begin{array}{l}
q_{H 1}=V-\frac{p_{H 1}-p_{L 0}}{1-\lambda_{1}}+\frac{\mu\left(q_{H 1}-\lambda_{1} q_{L 1}\right)}{1-\lambda_{1}} \\
q_{L 1}=\frac{p_{H 1}-p_{L 0}}{1-\lambda_{1}}-\frac{p_{L 0}}{1-\lambda_{1}}-\frac{\mu\left(q_{H 1}-\lambda_{1} q_{L 1}\right)}{1-\lambda_{1}}
\end{array}\right.
$$

Determining the low version quality discount based on the total market demand.

$$
\begin{gathered}
p_{H 1}^{*}=\frac{V}{2}+\frac{p_{L 0}}{1-\mu}-\frac{V(1-\mu) p_{L 0}}{2 p_{L 0}+A_{1}} \\
\lambda_{1}^{*}=\frac{2 p_{L 0} A_{2}}{2 p_{L 0}+A_{1}} \\
\left\{\begin{array}{l}
q_{H 1}^{*}=\frac{V}{2(1-\mu)}+\frac{A_{1}}{2 A_{2} \mu} \\
q_{L 1}^{*}=\frac{V(1-2 \mu)}{2 A_{2}}-\frac{p_{L 0}}{A_{3}}-\frac{A_{1}(1+\mu)}{2 A_{3} \mu} \\
q_{1}^{*}=\frac{V(2-3 \mu)}{2 A_{2}}-\frac{p_{L 0}}{A_{3}}-\frac{A_{1}}{A_{3}} \\
\Pi_{1}^{*}=\frac{V\left[V \mu(2-\mu)+4 p_{L 0}\right]}{4(1-\mu)}-\frac{p_{L 0}^{2}}{A_{3}}+\frac{A_{1}\left[V(1-\mu)-2 p_{L 0}\right]}{4 A_{3}} \\
+\frac{V^{2}(1-\mu)\left[V \mu^{2}(1-\mu)-A_{1}\right]}{4\left[V \mu \mu^{2}(1-\mu)-2 p_{L 0}\right]} \\
\frac{\partial p_{H 1}^{*}>0, \frac{\partial \Pi_{1}^{*}}{\partial \mu}>0, \frac{\partial q_{H 1}^{*}}{\partial \mu}>0, \frac{\partial q_{L 1}^{*}}{\partial \mu}<0}{\partial \mu}, A_{1}^{*}=(1-\mu)^{2}, A_{3}=(1-\mu)^{3}, A_{4}=(1-\mu)^{4}
\end{array} .\right.
\end{gathered}
$$

Proposition 1: When the provider chooses to sell both high and low versions, only when the network externality is met $0<\mu<\frac{1}{2}$, the demand for lower version products is greater than zero.

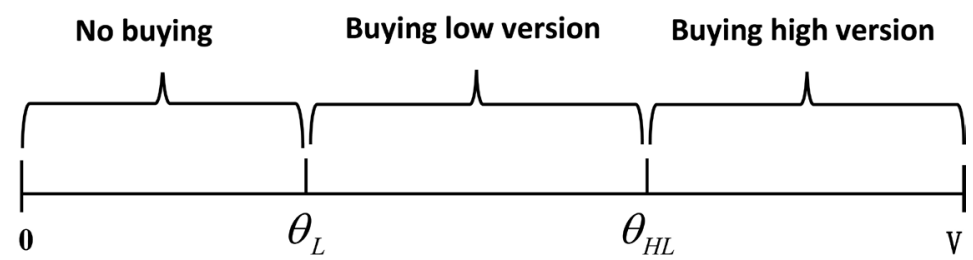

Figure 1. The consumer r's decision when simultaneous selling the high and low versions. 
When $q_{L 1}^{*} \geq 0$, the network externality is met $0<\mu<\frac{1}{2}$. Proposition 1 shows that in the case of a versioning strategy, when the provider chooses to sell both high and low versions, it is possible to obtain more buyers only when the network externality is small.

Proposition 2: If the high and low versions are sold at the same time, the quality discount for the lower version is $\lambda_{1}^{*}=\frac{2 p_{L 0} A_{2}}{2 p_{L 0}+A_{1}}$. At this time, the total market demand was maximized, but it still failed to reach full market.

When the network externality is small, the low version quality discount should be set at $\lambda_{1}^{*}=\frac{2 p_{L 0} A_{2}}{2 p_{L 0}+A_{1}}$. In the case of a small network externality, simultaneous selling high version and low version can't attract all potential buyers in the market.

\subsection{First Selling High Version, Then Selling Low Version}

Due to the asymmetric information, the consumers do not know that the provider will delay the sale of the low version product. When $\theta \in\left[\theta_{H}, \theta_{H L}\right]$, consumers who originally purchased a lower version product only changed to a higher version. When $\theta \in\left[0, \theta_{L}\right)$, consumers do not buy any products. When $\theta \in\left[\theta_{L}, \theta_{H}\right]$, consumers buy low version. When $\theta \in\left[\theta_{H}, V\right]$, consumers buy high version (Figure 2).

The demand function is

$$
\left\{\begin{array}{l}
q_{H 2}=V-p_{H 2}+\mu q_{H 2} \\
q_{L 2}=p_{H 2}-\frac{p_{L 0}}{\lambda_{2}}-\mu\left(q_{H 2}-q_{L 2}\right)
\end{array}\right.
$$

Determining the low version quality discount based on the total market demand.

$$
\begin{gathered}
p_{H 2}^{*}=\frac{V}{2}+\frac{p_{L 0}}{2(1-\mu)} \\
\lambda_{2}^{*}=\frac{2 p_{L 0} A_{2}}{\mu\left[V(1-\mu)(1-2 \mu)+p_{L 0}\right]} \\
\left\{\begin{array}{l}
q_{H 2}^{*}=\frac{V}{2(1-\mu)}-\frac{p_{L 0}}{2 A_{2}} \\
q_{L 2}^{*}=\frac{V(1-2 \mu)}{2(1-\mu)}+\frac{p_{L 0}}{2 A_{2}} \\
q_{1}^{*}=V
\end{array}\right.
\end{gathered}
$$

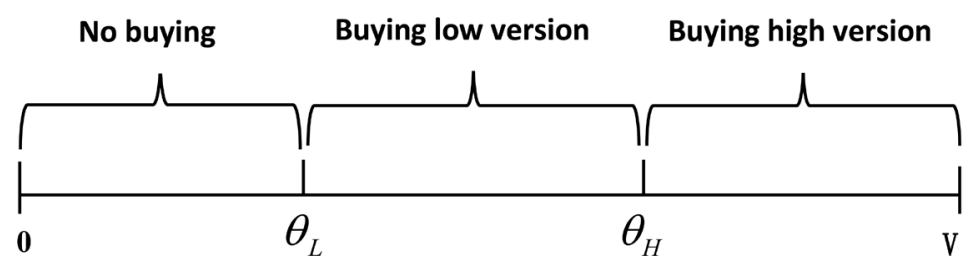

Figure 2. The consumer r's decision when first selling high version, then selling low version. 


$$
\begin{gathered}
\Pi_{2}^{*}=\frac{V\left[V+2 p_{L 0}(1-2 \mu)\right]}{4(1-\mu)}+\frac{p_{L 0}^{2}(1-2 \mu)}{4 A_{3}} \\
\frac{\partial p_{H 2}^{*}}{\partial \mu}>0, \frac{\partial \Pi_{2}^{*}}{\partial \mu}>0, \frac{\partial q_{H 2}^{*}}{\partial \mu}>0, \frac{\partial q_{L 2}^{*}}{\partial \mu}<0
\end{gathered}
$$

Proposition 3: The purchaser sells the lower version after selling the high version, and the lower version quality discount is $\lambda_{2}^{*}=\frac{2 p_{L 0} A_{2}}{\mu\left[V(1-\mu)(1-2 \mu)+p_{L 0}\right]}$. total demand is $V$, achieving full market. At this time, the high version price is $p_{H 2}^{*}=\frac{V}{2}+\frac{p_{L 0}}{2(1-\mu)}$.

Proposition 3 shows that the provider sells the low version after selling the high version, and can make the total demand reach the market full coverage. For high version products that are sold firstly, the provider can charge a higher price to increase profits. For the lower version products that are sold later, the remaining consumers are acquired, so that the market reaches full coverage.

Proposition 4: In the strategy of selling low versions after selling high versions, as the price of lower versions decreasing, the market demand for high versions increases, and the market demand for lower versions decreases.

When the low version is free, the market can still reach full coverage, at which time the total profit is $V^{2} / 4(1-\mu)$.

\subsection{First Selling Low Version, Then Selling High Version}

The utility function that consumers choose to different versions is:

$$
U=\left\{\begin{array}{l}
\left(\theta+\mu q_{H}\right)-p_{H}-\Delta u \\
\left(\theta+\mu q_{L}\right) \lambda-p_{L 0} \\
0
\end{array}\right.
$$

Defining $\theta_{3}=\frac{p_{H 3}-p_{L 0}}{1-\lambda_{3}}-\frac{\mu\left(q_{H 3}-\lambda_{3} q_{L 3}\right)}{1-\lambda_{3}}+\frac{\Delta u}{1-\lambda_{3}}, \Delta u>0$ indicates the waiting cost of preferring a high version. When $\theta \in\left[0, \theta_{L}\right)$, consumers do not buy any products. When $\theta \in\left[\theta_{L}, \theta_{3}\right]$, consumers buy low version. Due to information asymmetry, the consumers do not know that the provider will delay the sale of the high version product. When $\theta \in\left[\theta_{H L}, \theta_{3}\right]$, if their waiting cost is greater than the waiting cost, they will choose to purchase the low version, otherwise they will wait for the high version. When $\theta \in\left[\theta_{3}, V\right]$, consumers buy high version (Figure 3).

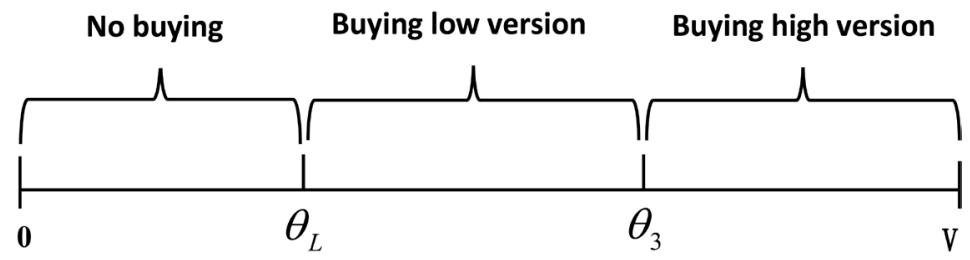

Figure 3. The consumer r's decision when first selling low version, then selling high version. 
The demand function is

$$
\left\{\begin{array}{l}
q_{H 3}=V-\frac{p_{H 3}-p_{L 0}}{1-\lambda_{3}}+\frac{\mu\left(q_{H 3}-\lambda_{3} q_{L 3}\right)}{1-\lambda_{3}}-\frac{\Delta u}{1-\lambda_{3}} \\
q_{L 3}=\frac{p_{H 3}-p_{L 0}}{1-\lambda_{3}}-\frac{p_{L 0}}{1-\lambda_{3}}-\frac{\mu\left(q_{H 3}-\lambda_{3} q_{L 3}\right)}{1-\lambda_{3}}+\mu q_{L 3}+\frac{\Delta u}{1-\lambda_{3}}
\end{array}\right.
$$

Determining the low version quality discount based on the total market demand.

$$
\begin{aligned}
& p_{H 3}^{*}=\frac{V}{2}+\frac{p_{L 0}}{1-\mu}-\frac{V(1-\mu) p_{L 0}}{2 p_{L 0}+A_{5}}-\frac{\Delta u}{2} \\
& \lambda_{3}^{*}=\frac{2 p_{L 0} A_{2}}{2 p_{L 0}+A_{5}} \\
& \left\{\begin{array}{l}
q_{H 3}^{*}=\frac{V}{2(1-\mu)}+\frac{A_{5}}{2 A_{2} \mu}-\frac{\Delta u}{2(1-\mu)} \\
q_{L 3}^{*}=\frac{V(1-2 \mu)}{2 A_{2}}-\frac{p_{L 0}}{A_{3}}-\frac{A_{5}(1+\mu)}{2 A_{3} \mu}+\frac{\Delta u}{2 A_{2}} \\
q_{3}^{*}=\frac{V(2-3 \mu)}{2 A_{2}}-\frac{p_{L 0}}{A_{3}}-\frac{A_{5}}{A_{3}}+\frac{\mu \Delta u}{2 A_{2}}
\end{array}\right. \\
& \Pi_{3}^{*}=\frac{V\left(4 p_{L 0}-2 \Delta u\right)}{4(1-\mu)}-\frac{p_{L 0}^{2}}{A_{3}}+\frac{A_{5}\left[V(1-\mu)-2 p_{L 0}\right]}{4 A_{3}}+\frac{\Delta u^{2}}{2(1-\mu)}-\frac{A_{5} \Delta u}{2 A_{2} \mu}+\delta \\
& \delta=\frac{V^{2}(1-\mu)\left\{V \mu^{2}(1-\mu)^{2}-\mu\left[V \mu^{2}(2-\mu)^{2}-\Delta u\right]+A_{5}\right\}+2 V^{2} p_{L 0} \mu(2-\mu)}{4(1-\mu)\left[(V \mu-\Delta u) \mu(1-\mu)-2 p_{L 0}\right]} \\
& \frac{\partial p_{H 3}^{*}}{\partial \mu}>0, \frac{\partial \Pi_{3}^{*}}{\partial \mu}>0, \frac{\partial q_{H 3}^{*}}{\partial \mu}>0, \frac{\partial q_{L 3}^{*}}{\partial \mu}<0 \\
& A_{5}=\sqrt{2(V \mu-\Delta u) p_{L 0}} \sqrt{\mu(1-\mu)}
\end{aligned}
$$

Proposition 5: If first sell the low version and then sell the high version, the quality discount of low version is $\lambda_{3}^{*}=\frac{2 p_{L 0} A_{2}}{2 p_{L 0}+A_{5}}$. At this time, with the waiting cost increasing, the price of the high version decreases, and the total market demand increases.

This is due to the asymmetric information, some consumers will not wait for the delayed high version because of the high waiting cost. They will choose to the low version.

\section{Analysis}

Considering the comparison of the above three sales orders, we will show the results in Tables 1-3.

Consider the comparison between the high version pricing and the total profits, which can be obtained from Table 1 :

Proposition 6: $p_{H 3}^{*}<p_{H 1}^{*}<p_{H 2}^{*} ; \Pi_{H 3}^{*}<\Pi_{H 1}^{*}<\Pi_{H 2}^{*}$.

Proposition 6 shows that for high version selling firstly, the provider obtain 
Table 1. Pricing and profit differences in three different sales orders.

\begin{tabular}{ccc}
\hline Different sales orders & High version price & profit \\
\hline Simultaneous selling & $\frac{V}{2}+\frac{p_{L 0}}{1-\mu}-\frac{V(1-\mu) p_{L 0}}{2 p_{L 0}+A_{1}}$ & $<\frac{V^{2}}{4(1-\mu)}$ \\
$\begin{array}{c}\text { First high version } \\
\text { then low version }\end{array}$ & $\frac{V}{2}+\frac{p_{L 0}}{2(1-\mu)}$ & $>\frac{V^{2}}{4(1-\mu)}$ \\
$\begin{array}{c}\text { First low version } \\
\text { then high version }\end{array}$ & $<\frac{V}{2}+\frac{p_{L 0}}{2(1-\mu)}-\frac{V(1-\mu) p_{L 0}}{2 p_{L 0}+A_{1}}$ & $<\frac{V p_{L 0}}{1-\mu}$ \\
\hline
\end{tabular}

Table 2. Market share differences in three different sales orders.

\begin{tabular}{cccc}
\hline $\begin{array}{c}\text { Different sales } \\
\text { orders }\end{array}$ & High version demand & Low version demand & Total demand \\
\hline $\begin{array}{c}\text { Simultaneous } \\
\text { selling }\end{array}$ & $\frac{V}{2(1-\mu)}+\frac{A_{1}}{2 A_{2} \mu}$ & $\frac{V(1-2 \mu)}{2 A_{2}}-\frac{p_{L 0}}{A_{3}}-\frac{A_{1}(1+\mu)}{2 A_{3} \mu}$ & $\frac{V(2-3 \mu)}{2 A_{2}}-\frac{p_{L 0}}{A_{3}}-\frac{A_{1}}{A_{3}}$ \\
$\begin{array}{c}\text { First high } \\
\text { version }\end{array}$ & $\frac{V}{2(1-\mu)}-\frac{p_{L 0}}{2 A_{2}}$ & $\frac{V(1-2 \mu)}{2(1-\mu)}+\frac{p_{L 0}}{2 A_{2}}$ & $V$ \\
$\begin{array}{c}\text { First low } \\
\text { version }\end{array}$ & $<\frac{V}{2(1-\mu)}+\frac{A_{1}}{2 A_{2} \mu}$ & $>\frac{V(1-2 \mu)}{2 A_{2}}-\frac{p_{L 0}}{A_{3}}-\frac{A_{1}(1+\mu)}{2 A_{3} \mu}$ & $>\frac{V(2-3 \mu)}{2 A_{2}}-\frac{p_{L 0}}{A_{3}}-\frac{A_{1}}{A_{3}}$ \\
\hline
\end{tabular}

Table 3. Impact of network externalities on pricing strategies under three different sales orders.

\begin{tabular}{|c|c|c|c|c|}
\hline Different sales orders & High version price & profit & High version demand & Low version demanc \\
\hline Simultaneous selling & + & + & + & - \\
\hline $\begin{array}{l}\text { First high version } \\
\text { then low version }\end{array}$ & + & + & + & - \\
\hline $\begin{array}{l}\text { First low version } \\
\text { then high version }\end{array}$ & + & + & + & - \\
\hline
\end{tabular}

the highest price and the highest total profit. If the provider sells the high version first, because there is no competition of the low version in the market, a higher price can be charged.

Consider the comparison between high and low version demands and total demands, which can be obtained from Table 2:

Proposition 7: $q_{H 2}^{*}<q_{H 3}^{*}<p_{H 1}^{*} ; \quad q_{L 1}^{*}<q_{L 3}^{*}<p_{L 2}^{*} ; q_{1}^{*}<q_{3}^{*}<p_{2}^{*}$.

As you can see from Proposition 7, if selling a high version firstly, the high version does not attract the consumers the most, but the low version of the post sales attracts all the remaining consumers. For the simultaneous sale of high and low versions, the high version gets the highest market share and the low version gets the lowest market share. The sale of the high version firstly will be able to fully cover the market.

Proposition 8: The increase in network externalities will increase the price and demand for high version and total profits, but reduce the demand for low version.

Proposition 8 shows that as the externality of the network increasing, the price 
and sales of the version products will be increased, but the effect of the low version to expand the market share of the product is reduced. When the externality of network increases to a certain extent, the appeal of the low version will be weakened and even exit the market. Therefore, the versioning strategy does not always expand the market share of products. In reality, many information products with strong network externalities, such as some video, audio and online content products with head effects are only available in a single version.

\section{Conclusions and Managerial Implications}

In order to expand the market, providers usually offer different versions of information products to meet the needs of different consumers. In this paper, for the three different sales orders, the corresponding low version quality discount is determined, which maximizes the market coverage and gives the high version of the optimal pricing according to the maximum profit.

For the simultaneous sale of high and low versions, only when the network externalities are small, the low version is likely to attract consumers. At this time, it does not attract all potential consumers, and the market has not reached full coverage. But this strategy is not without any benefit. This strategy shows that consumers are buying more high version products. This is conducive to providers to attract core users of a certain scale for forming a good reputation.

For the sale of the low version after the sale of the high version, the corresponding low version quality discount can be used to achieve full coverage. The high version of the product is the most expensive, the low version has the highest market demand, and the optimal total profit is also the highest. For high version products that are sold first, because there is no competition of the low version, the provider can charge a higher price, thereby increasing profits. For the low version products that are sold later, all the remaining consumers are acquired, so that the market reaches full coverage. So it is the best strategy to choose to sell the high version first.

For the sale of the high version after the sale of the low version, the high version price and the total market demand are affected by the waiting cost. As the waiting cost increasing, the high version price decreases and the total market demands increase. At this time, the market demands of the low version will increase, while the market share of the lower version increasing greater than that reduced by the high version, so the total market share will increase.

Under the three sales strategies, as the externality of the network increasing, the price and demands of the high version increase, and the total profit also increases. With the low version of the demand reducing, the attraction to consumers is weakened, and even exited the market. Therefore, the versioning strategy does not always expand the market share of products.

\section{Future Research}

As an extension to our work, the study of quality selection and competition 
strategies for competitive market with network externalities is an important one. In the competitive situation, we can also consider the dynamic pricing of multi-period purchases, the cost of conversion of products and different qualities. These situations are more reflective of reality. In the market of information products, there are differences in the scale of enterprises, and the resulting economies of scale also affect the pricing and quality selection, which is another direction that this paper can consider.

\section{Acknowledgements}

The authors are grateful to Associate Professor Xiaode Zuo who consistently providing helpful comments on the survey development of this study.

\section{Conflicts of Interest}

The authors declare no conflicts of interest regarding the publication of this paper.

\section{References}

[1] Bakke, P. and Boom, A. (2001) Vertical Product Differentiation, Network Externalities, and Compatibility Decisions. International Journal of Industrial Organization, 19, 267-284. https://doi.org/10.1016/S0167-7187(99)00029-6

[2] Sundararajan, A. (2004) Managing Digital Piracy: Pricing and Protection. Information System Research, 15, 287-308. https://doi.org/10.1287/isre.1040.0030

[3] Bhargava, H.K. and Choudhary, V. (2004) Economics of an Information Intermediary with Aggregation Benets. Information Systems Research, 15, 22-36. https://doi.org/10.1287/isre.1040.0014

[4] Noh, Y.H. and Moschinl, G. (2006) Vertical Product Differentiation, Enter-Deterrence Strategies, and Enterquality. Review of Industrial Organization, 29, 227-252. https://doi.org/10.1007/s11151-006-9115-7

[5] Lee, K.B., Yu, S.Y. and Kim, S.J. (2006) Analysis of Pricing Strategies for E-Business Companies Providing Information Goods and Services. Computers \& Industrial Engineering, 51, 72-78. https://doi.org/10.1016/j.cie.2006.06.014

[6] Nobuo, M. (2007) Price and Quality Competition: The Effect of Differentiation and Vertical Integration. European Journal of Operation Research, 180, 907-921. https://doi.org/10.1016/j.ejor.2006.04.028

[7] Chen, Y.J. and Seshadri, S. (2007) Product Development and Pricing Strategy for Information Goods under Heterogeneous outside Opportunities. Information System Research, 18, 150-172. https://doi.org/10.1287/isre.1070.0119

[8] Wu, S. and Chen, P. (2008) Versioning and Piracy Control for Digital Information Goods. Operations Research, 56, 157-172. https://doi.org/10.1287/opre.1070.0414

[9] Bhargava, H.K. and Choudhary, V. (2008) Research Note: When Is Versioning Optimal for Information Goods? Management Science, 54, 1029-1035. https://doi.org/10.1287/mnsc.1070.0773

[10] Cheng, H.K. and Tang, Q.C. (2010) Free Trial or No Free Trial: Optimal Software Product Design with Network Effects. European Journal of Operational Research, 205, 437-447. https://doi.org/10.1016/j.ejor.2010.01.014

[11] Chappell, H.W., Guimaraes, P. and Ozturk, O.D. (2011) Confessions of an Internet 
Monopolist: Demand Estimation for a Versioned Information Good. Managerial and Decision Economics, 32, 1-15. https://doi.org/10.1002/mde.1513

[12] Li, M., Feng, H. and Chen, F. (2012) Optimal Versioning and Pricing of Information Products with Considering or Not Common Valuation of Customers. Computers \& Industrial Engineering, 63, 173-183.

https://doi.org/10.1016/j.cie.2012.02.014

[13] Hui, W., Yoo, B. and Tam, K.Y. (2012) Sell by Bundle or Unit?: Pure Bundling versus Mixed Bundling of Information Goods. Decision Support Systems, 53, 517-525. https://doi.org/10.1016/j.dss.2012.02.008

[14] Lambertini, L. and Tampieri, A. (2012) Low-Quality Leadership in a Vertically Differentiated Duopoly with Cournot Competition. Economics Letters, 115, 396-398. https://doi.org/10.1016/j.econlet.2011.12.096 